Session 1793

\title{
Evaluation Issues in the Renewal of Engineering Education: Lessons from NSF-Funded Projects
}

\author{
Michael S. Trevisan \\ Washington State University
}

\begin{abstract}
The field of engineering education is in the midst of reform. Support for these change efforts is available through competitive programs within the National Science Foundation (NSF). The requirement to evaluate funded projects, particularly for program improvement, is an expectation across agency programs, and critical for program development and attainment of program outcomes. Three NSF-funded engineering education projects are highlighted in this paper to illustrate the variety of reform-oriented projects supported by NSF as well as evaluation issues that challenge the success of these efforts. The projects include: (1) an engineering design curriculum development project that specified the design expectations for the first two years of engineering education, (2) a new master's program in opto-electronics, and (3) an IGERT project in environmental engineering. Evaluation issues faced by these projects are both technical and non-technical in nature and are central to useful evaluation work. These issues are not only present in NSF-funded projects but also within engineering programs more generally and thus, the NSF-funded projects serve to showcase evaluation challenges as engineering education continues its drive for reform. Recommendations are offered for meeting these challenges and improving evaluation capabilities in engineering education programs.
\end{abstract}

\section{Background}

The last decade in engineering education has seen considerable interest and work in the teaching and learning aspects of engineering education programs. Faculty across the country have engaged in systematic investigations of programs, revised curricula, piloted and instituted alternative teaching strategies, and developed educational competencies for the technical and professional practice components of engineering education programs ${ }^{1,2,3}$.

The focus on competencies has inevitably led to the need to develop and measure objectives, assess outcomes, and evaluate programs for improvement and accountability. Thus, assessment and evaluation have played an increasing role in support of the national drive to enhance the achievement and competence of graduates from engineering education programs. 
Evaluation of projects and programs is a relatively new endeavor for the engineering education community. Defining objectives, measuring outcomes, and choosing appropriate evaluation methodology, are examples of evaluation activities that many faculty may be facing for the first time.

In a recent study, McKenzie, Trevisan, Davis, and Beyerlein ${ }^{4}$ sent questionnaires to all accredited engineering programs in the United States asking about the kinds of student assessment and program evaluation activities used to support senior capstone design courses and projects. Respondents rated student assessment and program evaluation opportunities high with capstone design courses, particularly as it relates to ABET EC 2000 engineering criteria. Overwhelmingly, respondents rated their preparedness for evaluation activities as low. Most faculty were interested in collaboration and or training to increase their assessment and evaluation capabilities. Two hundred ninety eight faculty members responded, across 119 institutions, for an institutional response rate of $43 \%$. All major engineering disciplines were represented.

Findings from this study provide empirical evidence for the concern many engineering education faculty members have about how best to respond to evaluation expectations and opportunities. Although the McKenzie et al. study focuses on a specific component of engineering education, the capstone design course, it is reasonable to assume that faculty would respond similarly if asked the same questions about other aspects of engineering education programs.

The National Science Foundation (NSF) has provided powerful stimulus for renewal efforts in engineering education through competitive funding opportunities in a variety of agency programs. Most funding opportunities are offered through the Directorate for Engineering (ENG), Division of Engineering Education and Centers (EEC). Specialized funding opportunities also exist within other directorates, such as Education and Human Resources (EHR).

Recognizing the need for assistance, NSF programs have enhanced evaluation requirements to include a strong recommendation to obtain the services of an experienced evaluator. A recent announcement from the Combined Research-Curriculum Development (CRCD) program solicitation illustrates this feature (NSF 01-0139). The "evaluation" portion of Component 4 of the announcement, "Project Evaluation/Implementation/Dissemination," reads:

Projects supported under the CRCD program are inherently innovative and experimental in character. Thus, it is essential that the methodologies and results of each project be subjected to careful evaluation to ensure that:

- The objectives of the project are being met by resulting innovation.

- Effective measures for evaluation are considered in cooperation with persons experienced in educational assessment and evaluation; 
- The evaluation system includes: measurable objectives (for example, objectives for student learning); procedures to measure their achievement; a system for monitoring the progress of the project in relation to these measures.

- Reliable evaluation usually requires multiple measures. (p. 12)

The purpose of this paper is to document evaluation issues engineering education programs face in the context of reform oriented projects funded by NSF. The paper argues that the evaluation issues confronted as part of NSF funded projects are also issues that can be found more broadly in engineering education, particularly as the field continues to drive toward reform.

This paper will first provide a brief rationale and description of three projects funded by NSF at a research university in the Pacific Northwest. These projects illustrate the variety of ideas funded by NSF and the connection between these projects and reform of engineering education. The type of evaluation technical assistance provided and the challenges inherent in this work will be addressed. Recommendations for ongoing evaluation support of engineering education projects and programs are offered.

\section{Three Examples}

As mentioned, NSF has provided competitive financial support to engineering education programs as the field continues its reform efforts. This funding has been an important stimulus for programs working for change, and an attractive means to initiate the process. NSF funding not only brings needed monetary stimulus for innovative projects but also prestige and positive publicity for programs and institutions having won competitive support from NSF. While the majority of funding is focused on undergraduate education, opportunities for support of graduate education also exist.

The following discussion highlights three examples from one institution in the Pacific Northwest. Examples 1 and 2 were funded by ENG. Example 3 was funded by DGE. The project need, description, and sponsoring NSF program are provided.

Example 1 (integrated design): Regional implementation of transferable integrated design engineering education (36 months; start date: 7- 1- 1999) - Action Agenda for Engineering Curriculum Innovation (NSF 98-27)

Interest in engineering design education has grown for several years and continues to be a major feature of undergraduate engineering education reform. Design education has faced barriers of ill-defined outcomes, lack of assessments, and uncertainty regarding optimum instructional approaches ${ }^{5,6}$. Moreover, in some states, students do their first two years of education at one of several community colleges. In Washington State for example, more than $50 \%$ of the junior students at 4-year institutions complete the first two years of their education at one of 26 community colleges in the state ${ }^{7}$. Thus, the need to ensure comparable, quality design education at all institutions in this and similar states is a priority. 
In response to these circumstances, WSU and several other institutions in the state, obtained NSF funding to institutionalize a regional design education component for the undergraduate engineering experience. This project extended the work of a previous NSF funded project, which developed student objectives through faculty workshops for the first two years of engineering education, along with a preliminary assessment system to provide programmatic feedback ${ }^{8}$. During the current project the assessment system received further refinement and now consists of multiple measures that include short-constructed response items, a performance assessment requiring students to work in teams on design activities, and an essay to evaluate their team design experience. The assessment system has been piloted at several schools in the state and administered regularly by a growing number of engineering programs and institutions.

Example 2(opto-electronics): Opto-electronics M.Sc. Specialization at WSU (36 months; start date: 8-16-98) - Combined Research Curriculum Development (CRCD) Program (NSF 98-38)

The economy of the Inland Northwest has experienced limited growth in the high-technology sector. Several companies have investigated re-locating to the region or establishing start-up companies in the area. A key concern voiced by these companies is the need for a professional workforce in the region that can be drawn on to fill critical technical positions. In addition, there currently exists a dearth of trained individuals with expertise in optoelectronics, which is critical to many high-technology products and future development.

In response to regional high technology industry needs, a master's program in opto-electronics was established at WSU, combining the research strengths of the physics and electrical engineering departments. NSF funding was obtained to develop and support the initial stages of the program. Course and laboratory experiences are central to the program, and provided by the department of electrical engineering and computer science, as well as the physics department. This joint venture between the two departments observed their first cohort of students in fall, 1999.

Example 3(IGERT): Education of the next generation of environmental scientists and engineers (60 months; start date: 1-1-99) - IGERT (NSF 98-96)

Many environmental problems continue to evade solution. A key reason given for this state of affairs is that research on these problems is typically focused within discipline. A growing argument to stem this situation is to integrate scientific investigations across disciplines to better understand the phenomenon and contribute to broad, usable solutions. Interdisciplinary education and training of graduate students is thought to be essential to developing a cadre of professionals with the knowledge, skills, and disposition to work across disciplines.

In order to enhance the research capabilities of new scientists working on environmental problems, the WSU environmental engineering program obtained IGERT funding to provide unique graduate training experiences for qualified students. The program is a partnership among three colleges and eight departments on campus performing cutting-edge fundamental and applied research in chemical, physical, and biological aspects of environmental science. Students learn to work in interdisciplinary teams and approach environmental problems from this perspective. Specialized course work and mentoring are provided to students. In addition, 
laboratory rotations with participating faculty researchers, and a variety of national and international internship experiences in government and industry are also part of the graduate training program.

\section{Common Features}

These projects hold four features in common. One, these projects are based on competitive ideas embodied in successful proposals. Although numbers of proposals submitted and awarded are not available for the opto-electronics project, there were 105 proposals submitted for the integrated design project and only 5 funded (D. Davis, personal communication, November 7, 2003). The IGERT project was one of 17 projects funded from over 600 pre-proposals submitted $^{9}$. Thus, the quality of the ideas, and the means of expressing these ideas in the proposal process suggest high standards for these three projects.

Second, all projects maintain that as a result of participation, students will develop new competencies, competencies not possible through educational experiences currently offered in their respective engineering program. The integrated design project expected students to develop engineering education design competencies, particularly during the first two years of engineering education. The opto-electronics and IGERT projects expect students to develop competencies to work in cross-disciplinary teams, and obtain solutions through this format.

Third, these projects incorporated partnerships and collaborations in order to leverage impact and sustain changes. The integrated design project required collaboration across colleges on campus, as well as with other institutions in the state. The opto-electronics and IGERT projects required college and departmental collaboration across campus as well as partnerships with industry. And for the IGERT project, partnerships with regional and international laboratories were required.

Fourth, all projects had expectations for evaluation as required in the respective NSF program solicitation. The integrated design and opto-electronics projects had extensive requirements for evaluation that included the recommendation for assistance from an experienced evaluator. The program announcement for the IGERT project stated an expectation to evaluate the project but did not provide detail for this requirement.

\section{Evaluation Technical Assistance}

Evaluation technical assistance for these projects was provided by the Assessment and Evaluation Center (AEC) at Washington State University (WSU). The AEC operates out of the College of Education at WSU. The purpose of the center is to provide student assessment and program evaluation work to K-12 schools, state agencies, and university departments. Except for workspace, the AEC is externally funded through grants and contracts.

How the evaluation was initiated and the type of technical assistance required was different for each project. For the integrated design and opto-electronics projects, the AEC was involved with the development of the grant proposal by writing the evaluation section and negotiating budget for these tasks. For IGERT, the AEC was brought into the evaluation approximately two years after the project had started. 
For the integrated design project, the evaluator provided focused assistance by facilitating the development of a student assessment system. This work included the construction of a variety of assessments for engineering design, development of scoring criteria to evaluate student work, and evaluation of technical characteristics of the assessment, such as inter-rater reliability.

For the opto-electronics and IGERT projects, an eclectic evaluation strategy was employed, strategically applying a variety of quantitative and qualitative data collection methods. The evaluations for these projects differed as the evaluation plans responded to unique program components and outcomes in each project. All stages of the opto-electronics project were evaluated, including planning and implementation phases. For the IGERT project, the evaluator conducted previously specified data collection tasks. In addition, formative evaluation of various components of the project were negotiated and carried out.

\section{Issues in the Evaluation of Engineering Education Programs}

The following discussion provides an accounting of four evaluation issues encountered in the evaluation of projects detailed in this paper. These issues are: (1) confusion between ABET expectations and the role of evaluation, (2) achievement outcomes and student assessment, (3) partnerships and collaboration, (4) challenges with the evaluation design, and (5) insufficient support for the evaluation. While not comprehensive, the issues serve to highlight evaluation challenges as the field of engineering education continues on a steady course toward reform.

Note that the observations and insights are based on the author's work with the three examples documented in this paper. Discussions with engineering educators, NSF project officers, and evaluation professionals assisting engineering programs and projects, have also played a role in shaping the author's ideas.

This paper is offered in a spirit of cooperation and support to the engineering education community as it continues to tackle evaluation challenges. It is hoped that the subsequent discussion proves helpful to engineering educators as they work for renewal and change in engineering education programs, as well as pursue NSF funding to support these initiatives.

\section{Confusion Between ABET Expectations and the Role of Evaluation}

Revised undergraduate program accreditation requirements by the American Board for Engineering Technologies (ABET) has provided much of the leverage and motivation for outcomes ${ }^{10}$. Referred to as EC 2000, these expectations have moved away from previous criteria that focused on inputs and counts of program attributes, toward identification and measurement of outcomes ${ }^{11}$.

Despite these recent changes, ABET accreditation expectations have historically fostered the notion among many engineering educators that evaluation is done for an external audience, rather than tasks and activities designed to support program efforts. Many engineering educators across institutions within the integrated design project for example, thought evaluation activities in the context of project evaluation, despite being required by NSF, as a means to address ABET 
expectations for impending accreditation site visits. While this phenomenon is not unique to engineering educators, the role that evaluation can play in support of engineering projects and programs is stymied and marginalized by this phenomenon under the intense pressure to achieve and maintain accreditation.

Thus, the high stakes nature of ABET accreditation requirements has to some degree, undermined its own efforts to foster program improvement evaluation.

\section{Achievement Outcomes and Student Assessment}

Each project has at base a set of achievement outcomes students are expected to obtain at various points in their educational experience. Faculty across projects and disciplines experienced considerable difficulty developing sound outcomes and connecting student assessment strategies to measure these outcomes in a reasonable way. There are three aspects to this difficulty. First, the nature of the desired achievement outcomes is complex, multidimensional, and often ill defined, particularly outcomes associated with "soft skills." For instance, Example 1 maintained engineering design expectations for second year engineering students. Examples 2 and 3 require students develop unique problem solving skills, work collaboratively, and obtain a variety of additional context specific outcomes. Faculty struggled to define these outcomes and agree on descriptions and as a consequence, had difficulty measuring them.

Second, several faculty wanted realistic assessment of student outcomes. The integrated design project for instance, worked to provide design engineering education experiences for students, incorporating team approaches to solution of design problems. Some faculty proposed observation of students working in teams as a means of obtaining realistic, authentic assessment information. After considering logistical issues associated with observation, faculty realized the heavy cost of implementing this assessment approach and chose a less resource intensive but less meaningful strategy. In the end, faculty could not easily reconcile their desire for authentic student assessment experiences and data on the one hand, and resource constraints on the other, and were frustrated by this state of affairs.

Third, collecting student assessment data for program or project improvement made little sense to many of the faculty participating in these projects. While faculty were concerned for project impact and wanted to be accountable, collecting aggregated information across students or a sample of students, in order to obtain estimates of project impact, did not carry validity for them. As faculty responsible for the teaching of formal course work, their concern was most often focused on student assessment data that could be used for individual student course grades. As a consequence, some faculty viewed data collection in the context of a project as a means to obtain data for course grades. This was the case for integrated design as this project was focused on undergraduate preparation, dealt with aspects of curriculum present is some courses taught by participating faculty, and incorporated a significant amount of student assessment.

\section{Partnerships/Collaboration}

All projects required an extraordinary amount of collaboration and partnership. In addition, each stakeholder group maintained different means of operation as well as different expectations for 
the project. The need for collaboration and differences in operation and expectation created difficulty and sometimes frustration for project personnel working toward project outcomes.

The integrated design project had difficulty maintaining cooperative arrangements with other institutions within the state. This occurred between two- and four-year institutions, as well as among four-year institutions (institutions that typically compete with one another for enrollment, prestige and political support within the state). The opto-electronics and IGERT projects experienced some collaboration difficulty across departments and disciplines on campus (campus units that operate autonomously).

Projects were unprepared for the work of collaboration and partnerships. Departmental, unit, and institutional means of operation often played against collaboration, despite the desire to incorporate collaboration as a strong feature of each project.

\section{Challenges with the Evaluation Design}

All projects struggled to develop and support an appropriate evaluation design. This included three aspects. First, despite the need to focus on program and project improvement, the evaluation designs were largely constructed to provide outcome data for accountability purposes. The integrated design project developed measures to collect design outcome data, rather than data that could be used to inform classroom curriculum and instructional decisions. The optoelectronics and IGERT projects both worked to develop innovative ways to collect project outcome data but did not see the value in formative assessment to inform the ongoing operation of the project.

Second, all evaluations were to some degree over promised. Perhaps with motivation to ensure NSF about the quality and seriousness of their projects, project personnel proposed evaluations that could not be delivered. The IGERT project for example, proposed the collection of comparative evaluation data for IGERT and non-IGERT students. On surface, the plan to collect this data seemed reasonable. The plan was logical, well thought, and a creative idea to conduct an impact assessment. However, the plan called for the collection of unique data on students (e.g., job offers, salaries, publications, presentations), data not typically collected on many campuses. As a result, the strategy over estimated what could actually be accomplished from an evaluation point of view.

\section{Insufficient Support for the Evaluation}

All projects had limited budgets. Tradeoffs were also made among project components in establishing each budget. While this is common practice when establishing budgets, in this process, evaluation tasks and activities were often thought of as "extra" duties, duties that could be accomplished on top of the normal workload and project expectations. Thus, during budget decision-making, the evaluation component was under funded. Evaluations were under funded because of uncertainty surrounding the amount of money needed to carry out evaluation activities. 
In addition, the evaluator was sometimes brought into the evaluation well after the project had started. Evaluation activities were initiated or delayed until well into the project. In the case of the IGERT project, the evaluator was brought in to provide evaluation technical assistance two years into the project. Not requiring evaluation from the outset of the project unwittingly challenges the delayed evaluation for legitimacy, since its addition comes after the development of program infrastructure and implementation. Project personnel and units have already negotiated tacit expectations for the project and how they will relate to one another. As a consequence, the evaluator can be forced into a marginal position, leaving evaluation support for the project in a tentative and fragile state.

\section{Discussion and Recommendations}

Evaluation challenges inherent in engineering education programs can be formidable. Those documented in this paper illustrate the depth of these challenges and may resonate with engineering educators. As engineering education continues its course toward reform, the issues discussed in this paper may intensify. In addition, the issues addressed in this paper hold not only for NSF funded projects, but also the entire engineering education enterprise. Continued attention to meeting EC 2000 ABET accreditation requirements and the push to include nontechnical skills in the curriculum places priority on specifying student objectives, program goals, and measuring outcomes, tasks many engineering faculty feel unprepared to conduct ${ }^{4}$. In addition, some faculty in nearly every program will view evaluation compelled by ABET as a means of placating an external audience, rather than a strategy to improve program outcomes. Industry partnerships, which have always been part of engineering education, and cooperative arrangements with other colleges and institutions, continue to have urgency among engineering programs, regardless of the existence of NSF funded projects. These collaborations have become part of the infrastructure (albeit unsteady) of engineering education. And whether evaluation is required for a funded project or simply as part of routine programmatic maintenance, establishing a supportive budget for these activities will continue to be an issue.

From experiences working to assist engineering educators on NSF-funded projects, five strategies have been identified that have near or long term payoff in meeting evaluation challenges addressed in this paper. These strategies include: (1) stay abreast of NSF resources and expectations, (2) develop evaluation capacity through training, (3) pursue early involvement of evaluators, (4) lay groundwork for partnerships and collaboration, and (5) involve program personnel in evaluation planning. Each is discussed below.

\section{Stay Abreast of NSF Resources and Expectations}

As part of a 10-year effort to support the evaluation of NSF educational projects a variety of resources have been developed and are currently available. In particular, the Research, Evaluation, and Communication Division recently released a website on evaluation of projects with a variety of links that could be helpful in developing evaluations ${ }^{12}$ (see www.her.nsf.gov/rec/main.asp). In addition, the previously published and widely circulated "User-Friendly Handbook for Project Evaluation," can be obtained through the NSF website (see www.her.nsf.gov/RED/EVAL/handbook/handbook.htm). Evaluation workshops are also under development. Thus, engineering educators have at their disposal a growing list of resources 
offered by NSF that could be used to assist with the development of grant proposals and the evaluation of projects.

A recent report concerning evaluation of projects within EHR underscores the concern and commitment NSF has for evaluation of projects ${ }^{13}$. A sample of NSF program officers and principal investigators funded through the EHR Directorate were asked a variety of questions related to evaluation of projects. The findings suggest that rigor of the evaluation of funded projects continues to be high, in large part due to increased expectations by NSF. In addition, a variety of ways evaluations could be improved (e.g., systematic evaluation requirements across programs, requiring projects budget for evaluation, resources to assist PI's develop evaluation plans) were offered ${ }^{13}$.

It is recommended that engineering educators stay abreast of NSF's work to increase the quality of project evaluation. In this way, engineering educators can develop competitive ideas for funding, strengthened by current NSF expectations for evaluation. Moreover, the evaluation ideas, models, training materials and workshop opportunities offered by NSF can also be used to support ongoing programmatic activities. Thus, attending to NSF's work to support educational projects and programs can have a twofold benefit for engineering educators as they work for program renewal and seek NSF funding to support and galvanize this effort.

\section{Develop Evaluation Capacity Through Training}

The need for evaluation capacity, that is, the knowledge, skills, and infrastructure needed to conduct effective evaluation, has never been greater for the engineering education community. Evaluation training is a key feature of evaluation capacity development. Thus, evaluation training of engineering educators is recommended. Ideas such as purposes for evaluation, developing and assessing project objectives and goals, utilizing evaluation data, and reporting results to a variety of stakeholders could productively be incorporated into evaluation training and workshops (see www.her.nsf.gov/rec/main.asp for listing of future NSF-sponsored evaluation workshops for principal investigators). And since attainment of achievement outcomes consistently cuts across projects and programs, training in the fundamentals of student assessment could also be incorporated into evaluation training experiences.

Evaluation training that tends to the issues of purpose may help to mitigate the notion of evaluation being done only for an external audience. Distinctions between evaluation for program improvement, and evaluation for accreditation (e.g., ABET), could help faculty view certain types of evaluation as beneficial to program initiatives and outcomes. Moreover, evaluation training that deals with the development of effective, realistic designs might also help faculty to construct evaluation plans that are not over promised but instead, useful to them as educators as they work to refine their program.

\section{Pursue Early Involvement of Evaluators}

Early involvement of an experienced evaluator is recommended for all projects or programs, regardless of the degree of innovation or its stage in development. Early involvement of 
evaluators will help to ensure that the evaluation plan is appropriate, useful, not over promised, and has sufficient budget to support the work.

In addition, evaluators working to assist innovative projects or programmatic initiatives, such as projects funded through IGERT or new senior capstone design experiences, will need to devise an evaluation plan to support programs, given their innovative nature, and sometimes fragile state, particularly in the early stages of the project or program. A focus on evaluation planning and implementation could be a useful strategy.

\section{Support Partnerships and Collaboration}

In a recent article, Brinkerhoff ${ }^{14}$ described problems associated with collaboration and partnerships, including idealistic definitions that are not easily operationalized, definitions that are not universally appropriate, and definitions whose justification is subjective and value-based. Coupled with a national focus on outcomes, most collaborative relationships lack the support and insight needed for positive arrangements, and necessary for attainment of outcomes. And ironically, despite the push for partnerships as a means to attain better outcomes, little evidence exists that partnerships, particularly in the nonprofit sector, are actually beneficial as proponents argue.

Given the current state of partnerships, while honoring the promise partnerships hold for increased outcomes, Brinkerhoff offers an assessment framework that could be employed to support partnerships, filling a void in the literature, and providing a practical tool for program personne $^{14}$. Given the fragile and dynamic nature of collaborative arrangements, the framework is developmental and process oriented. This framework may be of use to program personnel in engineering education programs and projects that almost uniformly, rely, at least in part, on partnerships to achieve their outcomes.

\section{Involve Program Personnel in All Aspects of the Evaluation}

With the expectation to evaluate programs and projects for continuous improvement, and therefore the need for program staff to utilize evaluation data, the role and approach the evaluator takes is an important factor to consider when assisting engineering education programs.

Perhaps the most common approach employed by educational projects and programs of any kind is to obtain an outside evaluator, who develops and conducts an evaluation, with little involvement from program personnel. The idea with this approach is that the evaluator can maintain objectivity by remaining outside the program. This objectivity is thought necessary for credible findings, particularly in an era of accountability.

However, evaluation information generated by an external evaluator is often seen by program personnel as unconnected to programmatic needs, and sometimes, irrelevant. The literature suggests that for evaluation utilization to occur, program personnel must be intimately involved in the development of the evaluation plan, data collection, and analysis ${ }^{15}$. In other words, involvement by program personnel in all aspects of the evaluation increases the relevance of evaluation findings for those who closely work with the day-to-day operation of the project or 
program. Program personnel therefore, value the evaluation findings and are more likely to act on them.

Engineering educators can begin to deal with this dynamic by knowing that NSF typically employs outside evaluators to evaluate the portfolio of projects that are funded by a NSF program. Accountability to congress, NSF, and taxpayers is obtained through this evaluation process. As a result, engineering programs can focus on evaluation that serves program improvement (unless the request for proposal specifies otherwise). Ideas and models that employ evaluators to work side-by-side with program personnel as part of a design team may have merit as these approaches are specifically designed to enhance evaluation utilization and organizational development ${ }^{16,17}$. And although objectivity may not be readily apparent in these approaches (since the evaluator works closely with program personnel) strategies can be employed to carefully handle data collection and analysis, and provide credible, relevant data.

These same ideas have relevance for programs working to meet university requirements for program evaluation and ABET expectations for accreditation. Involvement by program personnel, a focus on program improvement, and facilitation by an evaluator make a strong combination in support of program renewal and continuous improvement.

\section{Summary}

The projects discussed in this paper serve to support reform efforts (integrated design project) or connect engineering education programs to industry, community, and societal needs as evidenced by the opto-electronics and IGERT projects. These projects are representative of the type of engineering education initiatives supported by NSF. A test on the investment in these projects will be whether or not these efforts can be sustained and institutionalized. Evaluation for program improvement will have an important role in this regard.

The evaluation issues found in these projects are also evaluation issues present in engineering programs across the country, particularly in the context of new accreditation requirements and ongoing revision of programs. It is hoped that the lessons offered in this paper assist engineering educators effectively meet evaluation challenges as the field continues to face reform demands.

\section{Bibliography}

1. American Society for Engineering Education (1994). Engineering education for a changing world (Green Report).

2. Bjorklund, S. A., \& Colbeck, C. L. (2001). "The view from the top: Leaders' perspectives on a decade of change in engineering education." Journal of Engineering Education, 90(1): 13-19.

3. The Carnegie Foundation for the Advancement of Teaching (2001). Taking Stock - A look at engineering education at the end of the twentieth century and beyond.

4. McKenzie, L., Trevisan, M. S., Davis, D. C., \& Beyerlein, S. (2004). Capstone Design Courses and Assessment: A National Study. Paper to be presented at the American Society for Engineering Educators Annual Meeting.

5. Woods, D., R. (2000). “An evidence-based strategy for problem solving.” Journal of Engineering 
Education, 89(4): 443-460.

6. Davis, D. C., Gentili, K. L., Trevisan, M. S., \& Calkins, D. E. (2002). "Engineering design assessment processes and scoring scales for program improvement and accountability." Journal of Engineering Education, 91(2): 211-222.

7. Calkins, D. E., Davis, D. C., Crain Jr., R. W., Trevisan, M. S., and Gentili, K. L. (1996). “TIDEE: The first year of a design engineering educational partnership for Washington State." Proceedings of the Frontiers in Educational Conference.

8. Trevisan, M.S., Davis, D.C., Crain, R.W., Calkins, D.E. and Gentili, K.L. (1998). "Developing and assessing statewide competencies for engineering design." Journal of Engineering Education, 87 (2): 185 194.

9. Golde, C. M., \& Gallagher, H. A. (1999, November). "New modes of multidisciplinary doctoral education: The case of the water and society IGERT." Paper presented at the annual conference of the Association for the Study of Higher Education.

10. Accreditation Board for Engineering and Technology, Inc. (2000). Engineering criteria 2000.

11. Aldridge, M. D. \& Benefield, L. D. (1998, May-June). "A model assessment." ASEE Prism.

12. Katzenmeyer, C. G. (2002). Current professional infrastructure resources. In C. G. Katzenmeyer (Chair), Building Capacity for Science, Technology, Engineering, and Mathematics (STEM) Educational Evaluation. Symposium presented at the annual meeting of the American Evaluation Association.

13. Westat (2002). EHR Project Evaluation Review (Draft Report).

14. Brinkerhoff, J. M. (2002). "Assessing and improving partnership relationships and outcomes: A proposed framework." Evaluation and Program Planning, 25(3): 215-232.

15. Weiss, C. H. (1998). "Have we learned anything new about the use of evaluation?" American Journal of Evaluation, 19(1): 21-34.

16. Patton, M. Q. (1997). Utilization-focused evaluation: The new century text (3 ${ }^{\text {rd }}$ ed.). Thousand Oaks, CA: Sage.

17. Torres, R. T., \& Preskill, H. (2001). "Evaluation and organizational learning: Past, present, and future." American Journal of Evaluation, 22(3): 387-395.

\section{Bibliographical Information}

\section{MICHAEL S. TREVISAN}

Michael S. Trevisan is Associate Professor of Educational Psychology at Washington State University and Director of the Assessment and Evaluation Center in the College of Education. Dr. Trevisan has worked for over 10 years in measurement and evaluation, providing consultation to school districts, state agencies, and university departments. He has over 30 refereed publication in measurement and evaluation and teaches courses in these disciplines. 